\title{
Parasitic Contamination on Fresh Raw Vegetables Consumed in Yazd City, Iran, In during 2017-2018
}

\author{
Mohammad Reza Yavari ${ }^{1,2}$, Farzaneh Mirzaei ${ }^{3}$, Seyed Hossein Shahcheraghi², Ali Fattahi \\ Bafghi $^{2,4}$
}

1 Instructor, School of Medicine, Shahid Sadoughi University of Medical Sciences, Yazd, Iran

2 Infectious Diseases Research Center, Shahid Sadoughi Hospital, Shahid Sadoughi University of Medical Sciences, Yazd, Iran

3 Assistant Professor, Medical Parasitology Department, School of Medicine, Yazd Shahid Sadoughi University of Medical Sciences, Yazd, Iran

4 Professor, Medical Parasitology Department, School of Medicine, Yazd Shahid Sadoughi University of Medical Sciences, Yazd, Iran

*Corresponding Author: Dr. Ali Fattahi Bafghi, Department of Med Parasitology \& Mycology, School of Medicine, Yazd Shahid Sadoughi University of Medical Sciences, Yazd, Iran. Email: afbafghi@gmail.com Tel/Fax: +983538203414

Received: November 23, 2019; Accepted: December 30, 2019

\section{Abstract}

Consumption of fresh raw vegetables is very important in human nutrition. Raw vegetables is well known that is considered as an agent for transmission of several intestinal parasitical infections. Hence, this study determined raw vegetables in Yazd, Iran during 2017-2018. A total of 540 fresh vegetable samples (270 samples in spring and summer, and 270 samples for autumn and winter) were randomly collected. All samples were examined according to standard methods for detection of protozoan cysts, helminthes eggs as well as larva. The findings indicated that 139 cases $(25.7 \%)$ were contaminated with parasites. Spring onion showed the highest contamination rate by $43.33 \%$ in spring and summer, and $33.33 \%$ in autumn and winter. Conversely, the least contamination rate was seen in radish (20\%) in spring and summer, and basil (13.33\%) in autumn and winter. Moreover, Giardia (3.33\% in spring and summer, and $2.22 \%$ in autumn and winter) and Ascaris $(2.22 \%$ in spring and summer, and $1.85 \%$ in autumn and winter) comprised the majority of parasites in the examined samples. The findings of the study highlight the important role of raw vegetables in transmission of some intestinal parasites and imply the need for improving the sanitary conditions.

Keywords: Intestinal parasites, Protozoa, Helminthes, Raw consumed vegetable, Yazd.

\section{INTRODUCTION}

In many countries, consumption of raw vegetables is an important constituent of the diet. Raw vegetables are a great source of fiber, protein, minerals, vitamins, and fluid [1]. It can get contaminated with intestinal parasitic pathogens, including Viruses, bacteria and parasites during production, collection, transport or preparation of raw vegetables [2]. Prevalence of intestinal parasites is dependent on several factors including economic and social conditions, the use of water supplies contaminated with sewage for irrigation, untreated wastewater, to preserve and consumption of raw vegetables without proper washing [3]. Several parasites, including protozoa and helminthes have been shown to be transmitted through raw vegetables. In addition, many outbreaks of protozoan infections in humans have been related [4-5]. Over 40 million individuals are affected worldwide and $10 \%$ of the world population is at the risk of contamination [6]. There are limited studies on the possible contamination of freshly eaten raw vegetables in Iran and no previous studies have been conducted to evaluate the presence of parasitic contamination in vegetables in Yazd. Therefore, this study was designed to study the parasitic contamination on fresh raw vegetables consumed in Yazd, Iran, and risk for consumer during 2017-2018.

\section{MATERIALS AND METHOD}

This was a descriptive analytical study. A total of 540 samples of different raw consumed vegetables including leek, parsley, lettuce, coriander, radish, spring onion, tarragon, basil, and mint were randomly collected from markets with the same sellers between January 2017 and June 2018 (Fig1). At first a part of raw vegetables (250 $\mathrm{g}$ for all cases) and washed with physiological saline solution and the washing water was left about $24 \mathrm{~h}$ for sedimentation. It discarded the top water and 5 $\mathrm{ml}$ of the remaining washing water was centrifuged at $2100 \mathrm{~g}$ for 
5 min. The supernatant was exploded and the remaining was carefully collected, stained with Lugol, and examined through light microscopy [7]. The data were analyzed by SPSS16 applying $\times 2$ Test.

\section{RESULTS}

The presence of nonpathogenic and pathogenic parasites on several raw vegetables during one year is summarized in figures 1 and 2. Among 540 collected samples, 139 cases (25.7\%) showed contamination with parasites. Among the total samples in autumn and winter, $12.6 \%$ were infected with the nonpathogenic intestinal parasites and $9.2 \%$ were found to be contaminated with the pathogenic intestinal parasites (Fig. 1-2).

In contrast, $16.6 \%$ were specified to be infected with the nonpathogenic intestinal parasites in spring and summer, and $12.9 \%$ contaminated with the pathogenic parasites (Figure 3 ).

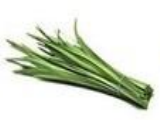

Leek

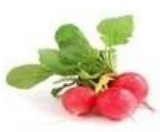

Radish
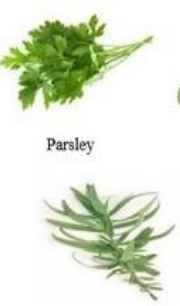

Tarragon

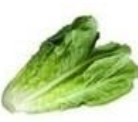

Lettuce

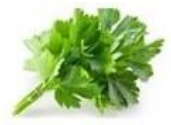

Coriander

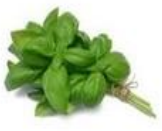

Basil

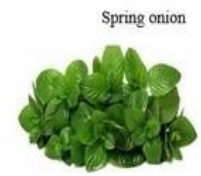

Mint
Figure 1: Eggs and cysts distribution of pathogen and non- pathogen parasites on fresh vegetables consumed in Yazd city (Iran) from spring, summer, autumn and winter during 2015-2016.

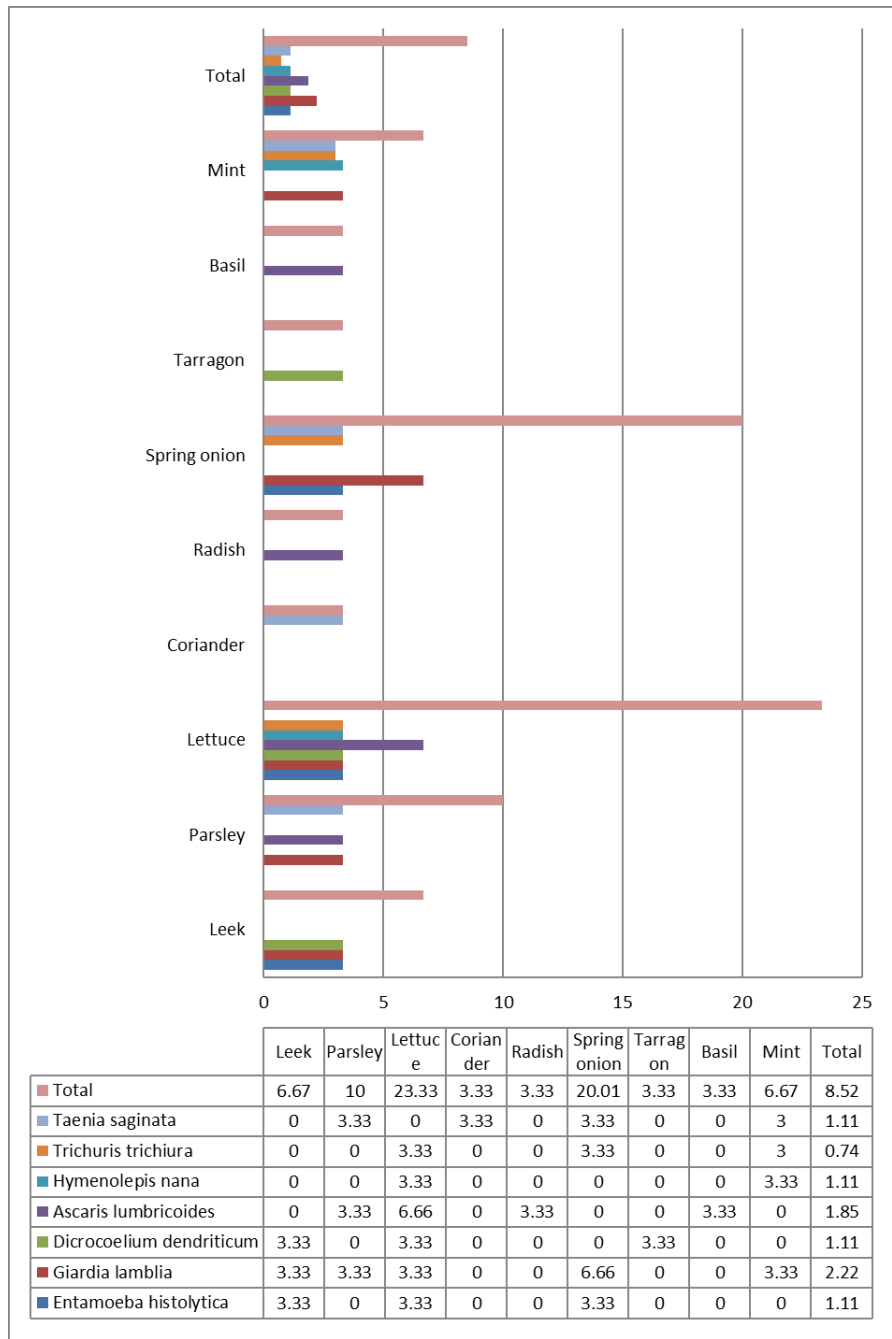

Figure 2: Distribution of Eggs and cysts pathogens parasites on fresh vegetables consumed in Yazd city (Iran) from autumn and winter during 2015-2016. 


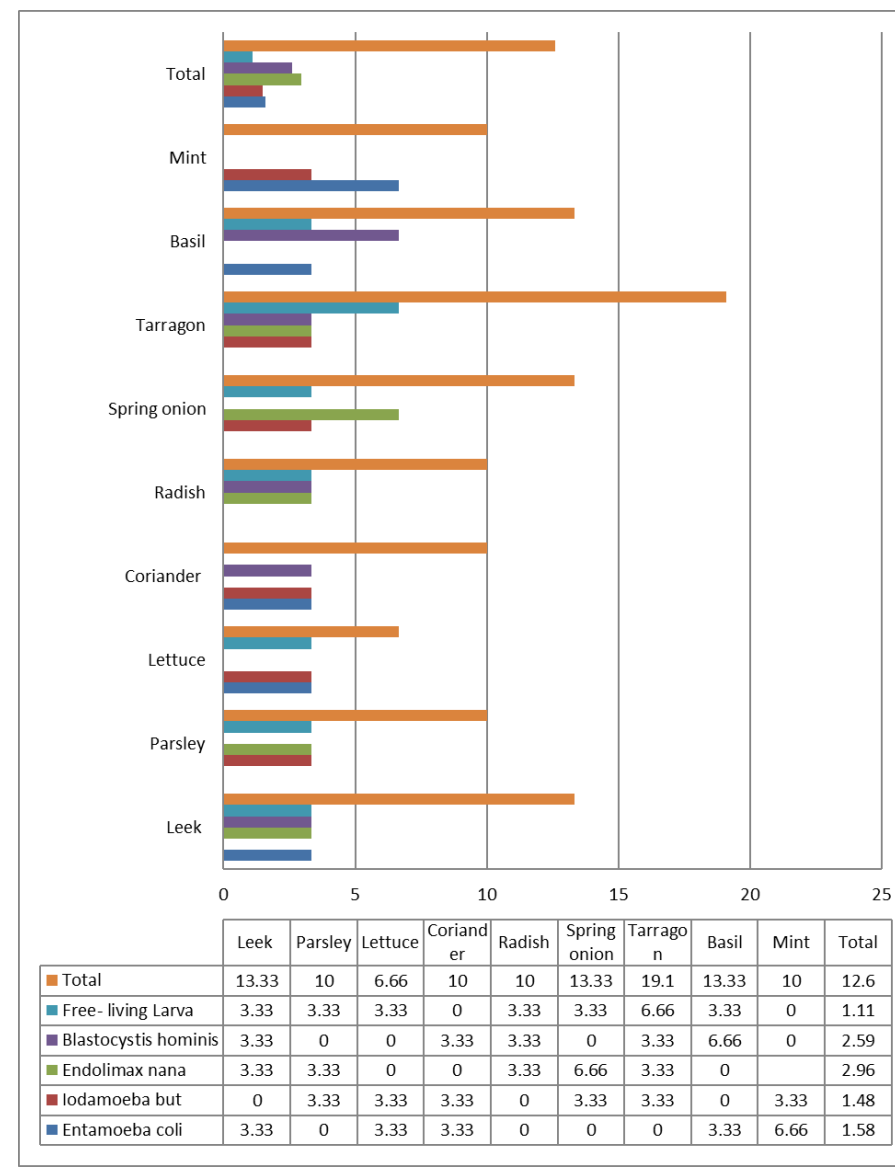

Figure 3: Eggs and cysts distribution of non- pathogen parasites on fresh raw vegetables consumed in Yazd city (Iran) from autumn and winter during 2015-2016.

In autumn and winter, spring onion was detected to be the most contaminated raw vegetable $(33.33 \%) \mathrm{p}<0.005$. Conversely, basil was shown to be the least contaminated sample (13.33\%) $\mathrm{p}<0.005$. In spring and summer seasons, the highest of contamination rate vegetables was detected in spring onion $(43.33 \%)$, while the lowest of contamination rate samples was detected in basil and radish (20\%). Also, the highest rate of parasitic contamination in raw vegetables was found in spring and summer seasons (29.63\%). Bio statistical analysis revealed that the rate of contamination in spring and summer seasons was significantly higher than that in autumn and winter seasons $(p<0.005)$.

\section{DISCUSSION}

Consumption of raw vegetables is considered as one of the important ways of transmission of parasitic contaminations [8]. Any epidemiological studies have shown that a large number of parasitic infestation cases are associated with untreated water reused in irrigation system [9-10]. Vegetables, especially salads such as lettuce, cabbage, and other wide-leafed raw vegetables are routes for transmission of intestinal parasitic infections. They have been demonstrated to be one of the sources of outbreaks on food-borne in developing countries [11-12]. Raw vegetables are contaminated before harvesting by contact with soiled ground, contaminated manure, sewage, irrigation water or directly from savage and domestic animals [13-14]. Therefore, determining the extent of vegetables contamination in the region can indicating the incidence of intestinal parasites among a community. $29.63 \%$ of green vegetables were contaminated with intestinal parasites in spring and summer, and $21.85 \%$ in autumn and winter. In addition, Bio statistical analysis revealed that the rate of contamination was significantly higher $(P<0.005)$ in spring and summer seasons than in autumn and winter seasons. This result was consistent with previous studies which showed that the prevalence of parasitic contamination of raw vegetables is higher in warm seasons than in cold seasons [7, 15]. In the present work, both pathogenic and nonpathogenic parasites were detected in raw vegetable samples. The pathogenic ones included Entamoeba histolytica, Giardia lamblia, Dicrosoelium dendriticum, Ascaris lumbricoides, hymenolepis nana, Trichuris trichiura, Taenia saginata, and nonpathogenic parasites were Entamoeba coli, lodamoeba butschli, Endolimax nana, Blastocystis hominis, Dientamoeba fragilis and Free-living larva. Giardia lamblia and Ascaris lumbricoides comprised the majority of pathogenic parasites. Giardia spp was the most prevalent parasite contaminating raw vegetable samples in spring and summer (3.33\%) and in autumn and winter $(2.22 \%)$. Prevalence rate of Giardia lamblia in other cities of Iran is The following is the following: vegetables imported to Ardabil 7\% and raw vegetables cultivated in Ardabil 8.9\% 7, Khorram Abad 6.9\% [16], Ahwaz 10\% [17], Tehran 6.5\% [18], Yasouj 11\% [19], Hamadan 5\% [20], and Jiruft 14\% [21]. Monge and Arias (1996) showed Infection of intestinal parasites in vegetables in Costa Rica that $5 \%$ of samples were contaminated with Giardia cysts. The rate of contamination with Giardia lamblia was $2.1 \%$ in raw fruits and vegetables in Norway [22-23]. Giardia spp. cysts were found in $6.7 \%$ of different raw vegetables in Egypt [24]. The present study demonstrated that $2.22 \%$ of raw vegetables in spring and summer, and $1.85 \%$ of raw vegetables in autumn and winter were contaminated with Ascaris lumbricoides. These results are consistent with the findings of other studies performed in Iran. Contamination with Ascaris lumbricoides eggs is in line. This value was $2 \%$ in Ardabil city [7], 2.5\% in Jiruft city [21], 5.8\% in Khorram Abad city [16] and 2.3\% in Qazvin city [25]. Ascaris lumbricoides eggs were detected in $20.3 \%$ of the examined samples in Egypt [24]. In India, Ascaris lumbricoides eggs were detected in $36 \%$ of the examined samples [26]. The results, showed that consumption of raw vegetables can threaten public health by transmission of intestinal parasites to humans. In conclusion, it is important to improve the sanitary conditions in the regions including proper treatment of wastewater used for irrigation of raw vegetables, improve the sanitary conditions in the areas where the raw vegetables consumed, make the consumers aware of the potential health subsequences of the intestinal parasites through consumption of raw vegetables as well as appropriate washing and disinfecting of vegetables before consumption. More research should be done on the pollution of irrigation and soil in farmland.

\section{CONCLUSION}

Prevention of contamination is the most effective way to reduce foodborne parasitic infection. Concerning the health risks associated with the consumption of contaminated raw vegetables, comprehensive health education should be given to the general public, especially consumers of raw vegetables. They should always adhere to the basic principle of food and personal hygiene, that is, thoroughly washing raw vegetables before eating and washing hands before meals. Sellers of raw vegetables should avoid mixing vegetables with soil when selling. The survey should also be conducted in different parts of the country. For a clearer view of this risk, quantitative analysis and more risk estimation should be considered.

\section{Acknowledgments}

The authors would like to acknowledge the Medical Parasitology 
and Mycology department, school of medicine, Shahid Sadoughi University of medical sciences, Yazd, Iran for their generous cooperation during this study. We are grateful to Mrs. Sayyedeh Zahra Hosseini and Mrs. Zahra Sadeghi the graduated experts of laboratory technology department. Thanks also are indebted to Yazd Guild herbs and vegetables for their participation in this study. The work presented in this paper was funded and grant based on a thesis submitted (No. 1422) by the Shahid Sadoughi University of medical sciences, Yazd, the Ministry of Health, Iran. The funders had no role in study design, data collection and analysis, decision to publish, or preparation of the manuscript.

\section{Conflict of Interest}

We declare that we have no conflict of interest.

\section{Financial Support}

None declared.

\section{REFERENCES}

1. Adamu NB, Adamu JY, Mohammed D. Prevalence of helminth parasites found on vegetables sold in Maiduguri, Northeastern Nigeria. Food Control 2012; 25: 23-26.

2. Abougrain AK, Nahaisi MH, Madi NS, Saied MM, Ghenghesh KS. Parasitological contamination in salad vegetables in Tripoli-Libya. Food Control 2010; 21: 760-762.

3. Slifko TR, Smith HV, Rose JB. Emerging parasite zoonoses associated with water and food. International journal for parasitology 2000; 30: 1379-1393.

4. Ebrahimzadeh A, Jamshidi A, Mohammadi S. The parasitic contamination of raw vegetables consumed in Zahedan, Iran. Health Scope 2013;1: 205-209.

5. Mintz ED, Wragg MH, Mshar P, Cartter ML, Hadler JL. Foodborne giardiasis in a corporate office setting. Journal of infectious diseases 1993;167: 250-253.

6. Abdussalam M, Käferstein F, Mott K. Food safety measures for the control of foodborne trematode infections. Food Control 1995; 6: 71-79.

7. Daryani A, Ettehad G, Sharif M, Ghorbani L, Ziaei H. Prevalence of intestinal parasites in vegetables consumed in Ardabil, Iran. Food Control 2008; 19: 790-794.

8. Anuar A, Ramachandran C. A study on the prevalence of soil transmitted helminths among lettuce leaves sold in local markets in Penang, Malaysia. The Medical journal of Malaysia 1997; 31: 262-265.

9. Bradely R, Hadidy S. Parasitic infection and the use of untreated sewage for irrigation of vegetables with particular reference to Aleppo. Syrian Public Health Engineering 1981; 9: 154-157.

10. Cifuentes E, Blumenthal U, Ruiz-Palacios G, Bennet S. Biological health risks associated with the composting of wastewater plant sludge. J Wat Poll Control Fed 1992; 56: 1269-1276.

11. Larkin E, Tierney J, Lovett J, Van Donsel D, Francis D, Jackson G. Land application of sewage wastes: potential for contamination of foodstuffs and agricultural soils by viruses, bacterial pathogens and parasites. State of Knowledge in Land Treatment of Wastewater, Int. Symp. 1978

12. Pires SM, Vieira AR, Perez E, Wong DLF, Hald T. Attributing human foodborne illness to food sources and water in Latin America and the Caribbean using data from outbreak investigations. International Journal of Food Microbiology 2012;152: 129-138.

13. Bryan FL. Diseases transmitted by foods contaminated by wastewater. Journal of Food Protection® 1977;40: 45-56.

14. Taban BM, Halkman AK. Do leafy green vegetables and their ready-to-eat [RTE] salads carry a risk of foodborne pathogens? Anaerobe 2011;17: 286-287.

15. Al-Megrm WI. Prevalence of intestinal parasites in leafy vegetables in Riyadh, Saudi Arabia. International Journal of Tropical Medicine 2010;5: 20-23.

16. Ezatpour B, Chegeni AS, Abdollahpour F, Aazami M, Alirezaei M. Prevalence of parasitic contamination of raw vegetables in Khorramabad, Iran. Food Control 2013;34: 92-95.

17. Akhlaghi L, Oormazdi $H$. Survey of parasitic infections of consumed vegetables in Ahwaz city. Proceeding of the 3rd National Iranian Congress of Parasitology.2000

18. Gharavi M, Jahani M, Rokni M. Parasitic contamination of vegetables from farms and markets in Tehran. Iranian Journal of Public Health 2002;31: 83-86.

19. Sarkari B. Survey of parasitic infections in consumed vegetables in Yasouj city. J Yasouj Univ Med Univ 1996;1: 31-36.

20. Sayyed Tabai J, Sadjjadi S. Parasitic infections of consumed vegetables in Hamadan city. Pajouhandeh J 1998;15: 267-271.

21. Zohour A, Molazadeh P. Prevalence of pathogenic parasites in consumed vegetables in Jiruft. Journal of Birjand University of Medical Sciences 2001;8: 10-13.

22. Monge $R$, Arias ML. Presence of various pathogenic microorganisms in fresh vegetables in Costa Rica. Archivos latinoamericanos de nutrición 1996; 46: 292-294.

23. Robertson L, Gjerde B. Isolation and enumeration of Giardia cysts, Cryptosporidium oocysts, and Ascaris eggs from fruits and vegetables. Journal of Food Protection $\AA^{2}$ 2000; 63: 775-778.

24. Said DES. Detection of parasites in commonly consumed raw vegetables. Alexandria Journal of Medicine 2012;48: 345-352.

25. Shahnazi $M$, Jafari-Sabet $M$. Prevalence of parasitic contamination of raw vegetables in villages of Qazvin Province, Iran. Foodborne pathogens and disease 2010;7: 1025-1030.

26. Gupta N, Khan D, Santra S. Prevalence of intestinal helminth eggs on vegetables grown in wastewater-irrigated areas of Titagarh, West Bengal, India. Food Control 2009; 20: 942-945. 